\title{
Characterization and use of functionalized carbon nanotubes for the adsorption of heavy metal anions
}

\author{
Yi-jun Xu, R. Arrigo, X. Liu, D.S. Su* \\ Department of Inorganic Chemistry, Fritz Haber Institute of the Max Planck Society, \\ Faradayweg 4-6, 14195 Berlin, Germany
}

*Corresponding author: e-mail dangsheng@fhi-berlin.mpg.de,

Received 28 November 2010, Available online 5 March 2011

\begin{abstract}
The Carbon nanotubes (CNTs) have been chemically functionalized with various oxygen-containing surface groups. The feature of abundant oxygen-containing surface functional groups on the functionalized CNTs is characterized by X-ray photoelectron spectroscopy and temperatureprogrammed desorption analysis. Results indicate that the functionalized CNTs have a superior adsorption capacity toward anionic chromate $\mathrm{CrO}_{4}{ }^{2-}$, a typical toxic heavy metal ion in waste water, as compared with the unmodified ones. The excellent adsorption ability of $\mathrm{CrO}_{4}{ }_{4}^{2-}$ is attributed to the interaction of $\mathrm{CrO}_{4}{ }^{2-}$ with the surface oxygen-containing functional groups on the modified CNTs. The functionalized CNTs can be potentially used as an alternatively viable and promising adsorbent for the removal of heavy metal anions in waste water.
\end{abstract}

Keywords: Carbon nanotube; $\mathrm{CrO}_{4}{ }^{2-}$; Adsorption; Chemically functionalization

\section{Introduction}

Considerable efforts have been made to focus on nanostructured carbon materials for their potential applications in numerous fields, such as microfilters, biology and medicine, nanoscale engineering and molecular electronics, hydrogen-storage devices, lithium battery, gas sensors, and catalysis [1-5]. . Carbon nanotubes (CNTs), as one of the representative paradigms among nanostructured carbon materials, continue to attract tremendous attention in the past two decades due to their unique physical and chemical properties [6-7]. In particular, chemical functionalization of CNTs can modify their physical and chemical properties, leading to the improvement of their performance for specific applications [8].Notably, some studies have indicated that functionalized CNTs are a promising candidate for the removal of trace amounts of toxic heavy metals in waste water[9], which represent an important environmental issue because of their toxic effects and accumulation throughout the food chain and hence in the human body [10-11]. It is also recognized that the adsorption of heavy metal ions from solution on CNTs is mainly dominated by the surface functional groups on CNTs [9].

However, earlier research works focused only on the adsorption of divalent cationic heavy metal ions [9]. In this study, we demonstrate that functionalized CNTs with abundant oxygen- containing surface groups exhibit the superior adsorption capability for anionic chromate $\left(\mathrm{CrO}_{4}{ }^{2-}\right.$ ), a typical heavy metal ion in waste water, from aqueous solution, as compared with the unmodified ones.

Water pollution by hexavalent chromium $\mathrm{Cr}^{6+}$ is of considerable concern because $\mathrm{Cr}^{6+}$ is a powerful epithelial irritant, is toxic to many plants, aquatic animals, and bacteria, and is confirmed to be a human carcinogenic substance [12-13]. Most of the industrial wastewater discharged into surface water contains $\mathrm{Cr}^{6+}$ even after a reduction treatment process to the trivalent state[14]. The disadvantage of the reduction treatment of $\mathrm{Cr}^{6+}$ to trivalent state is the high cost of chemicals used for the reduction process and incomplete conversion of $\mathrm{Cr}^{6+}$, which may produce toxic sludge because of the surface adsorption of $\mathrm{Cr}^{6+}$ onto the $\mathrm{Cr}^{3+}$ hydroxide precipitate. Therefore, it is highly desirable to explore other viable methods to remove $\mathrm{Cr}^{6+}$ in waste water. From the economy and efficiency point of view, surface adsorption by choosing potential adsorbent provides a feasible and promising alternative. The results presented in this work, for the first time, reveal that the functionalized CNTs are a promising and viable adsorbent for the removal of toxic chromate from aqueous solution. 

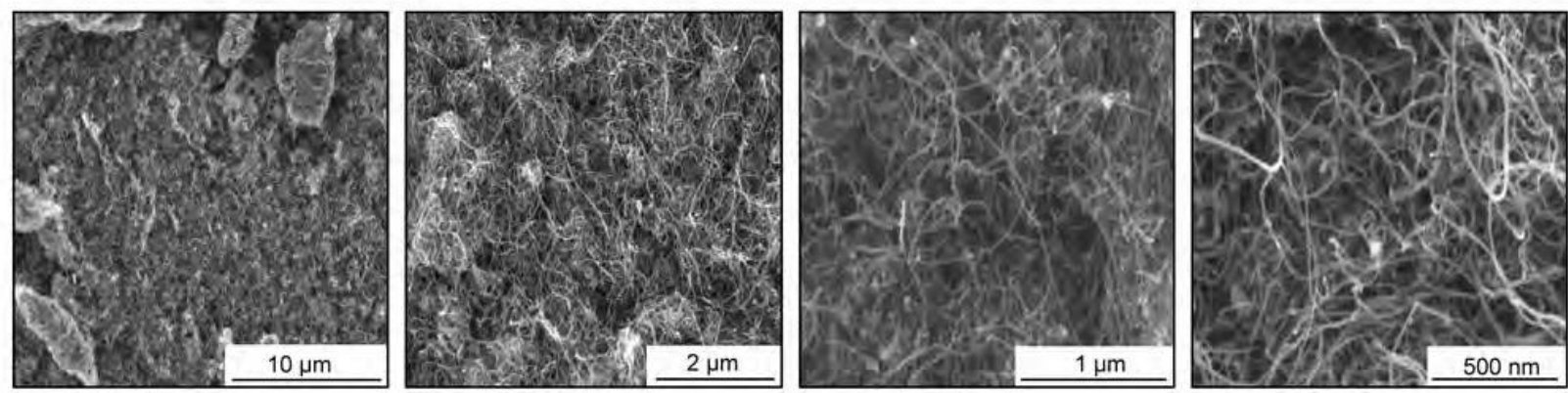

Fig. 1: SEM images of as received baytube CNTs at different resolutions
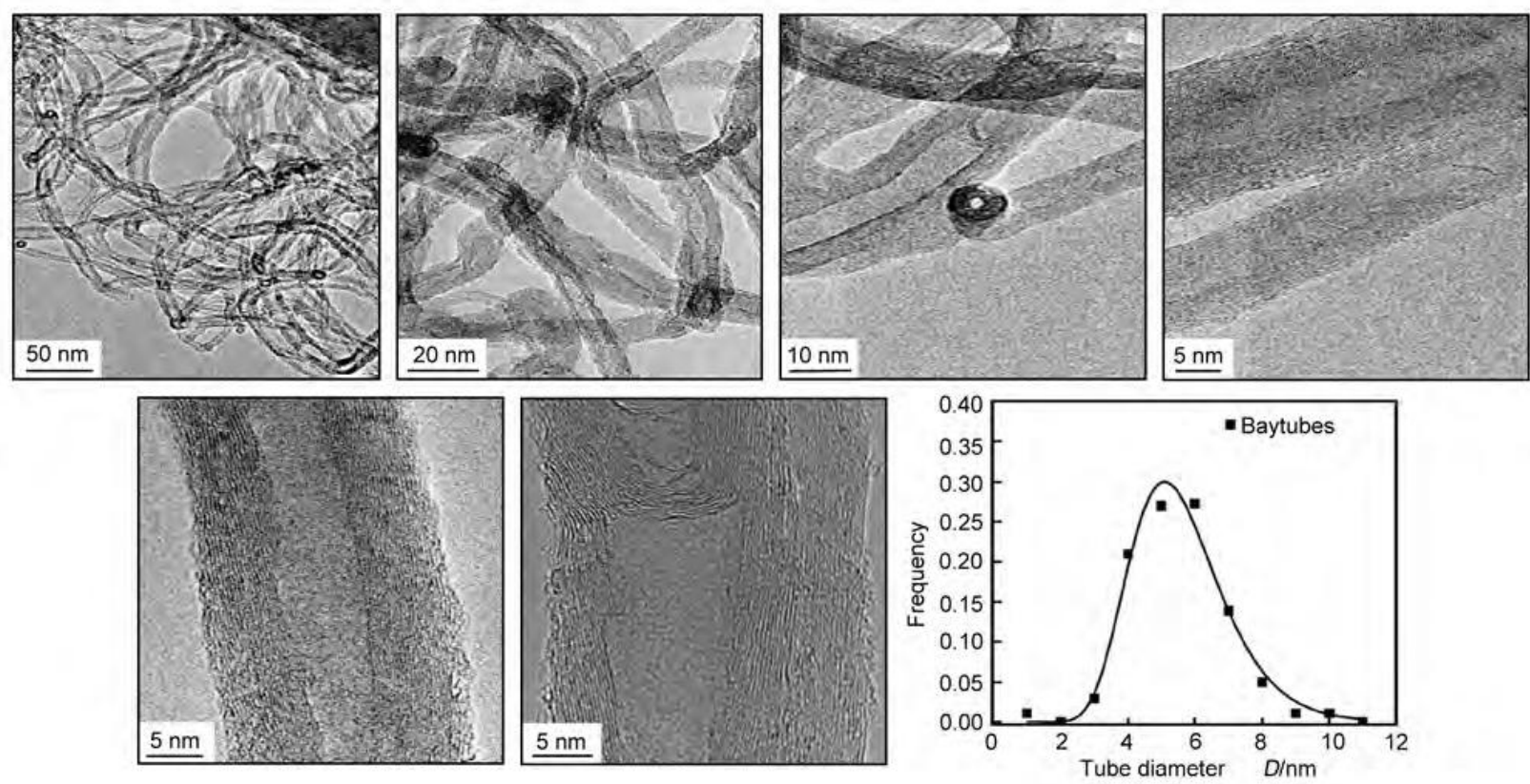

Fig. 2: TEM / HRTEM images at different resolutions and diameter distribution of as received baytube CNTs
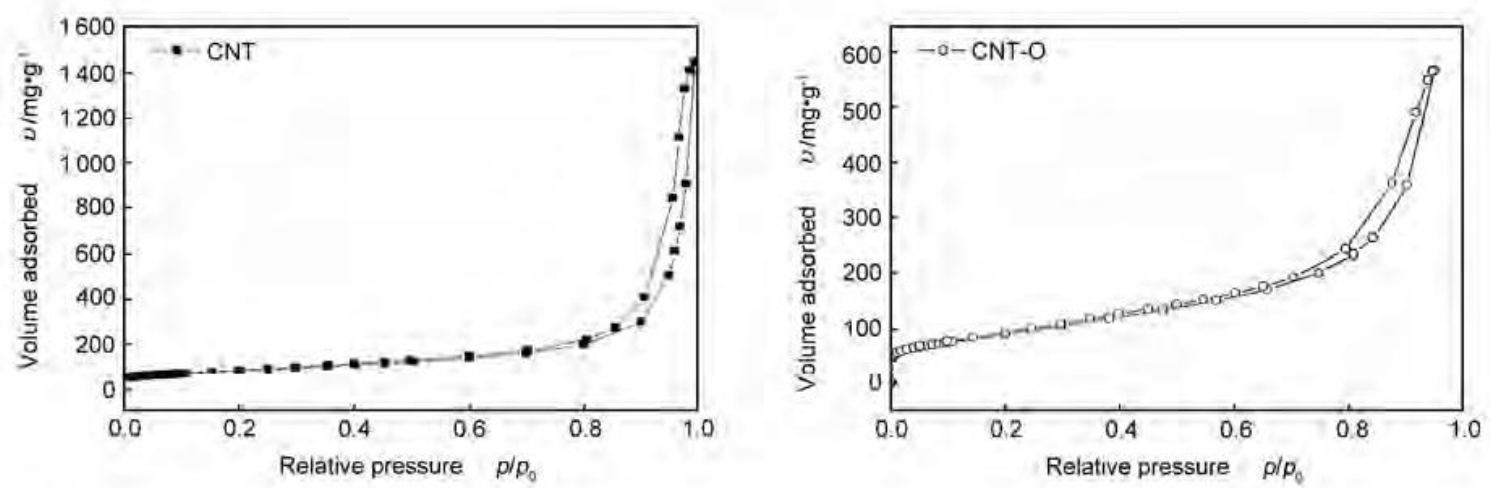

Fig. 3: BET adsorption isotherms of CNT and CNT-O 


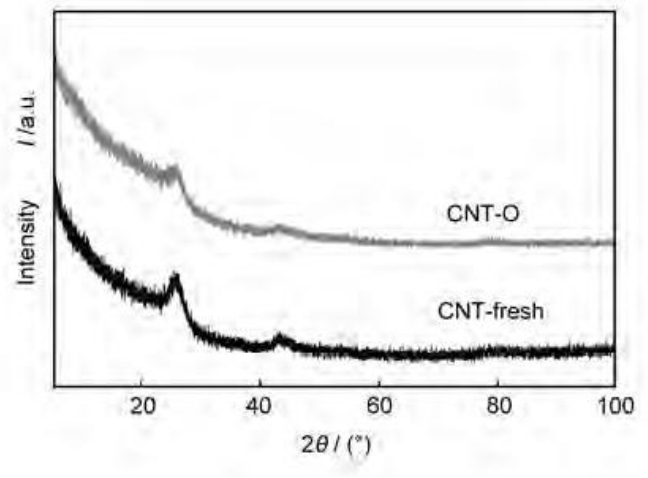

Fig. 4: XRD patterns of CNT and CNT-O

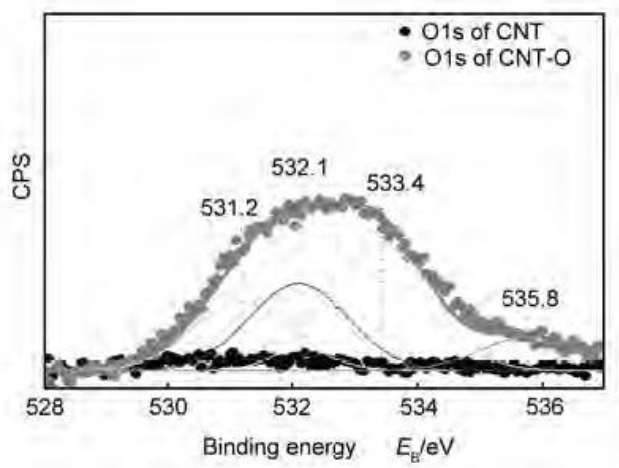

Fig. 5: XPS O1s spectra of CNT and CNT-O and fitting of O1s spectra of CNT-O using a multiple Gaussian function

\section{Experimental section}

CNTs are commercial multiwalled CNTs supplied by Bayer Material Science Company. Chemical functionalization of the as-received CNTs was carried out by introducing oxygen- containing functional groups with concentrated nitric acid $\left(\mathrm{HNO}_{3}\right)$. The as-received CNTs were refluxed in the concentrated $\mathrm{HNO}_{3}$ for $10 \mathrm{~h}$ under continuous stirring, followed by washing with distilled water completely and drying at $373 \mathrm{~K}$ overnight in a furnace. This method is also well utilized for oxidation of other carbon allotropes, such as activated carbons and fullerenes[15]. Such oxidation treatment of CNTs not only introduced different oxygencontaining functional groups onto the surface or inner matrix of CNTs but also removed the metal impurities inherently present in the as-received CNTs. For clarity, the asreceived CNTs are denoted as CNT and the functionalized ones as CNT-O.

Temperature-programmed desorption (TPD) were carried out in a quartz reactor connecting with a Quadrupole Mass Spectrometer 200 M2. Sample (20 mg) was loaded between two quartz wool plugs with helium flow at room temperature for $2 \mathrm{~h}$. After that, the temperature was increased to $830{ }^{\circ} \mathrm{C}$ with a ramp rate of 10

$\square \mathrm{C} / \mathrm{min}$ and a helium flow rate of $15 \mathrm{~mL} / \mathrm{min}$.
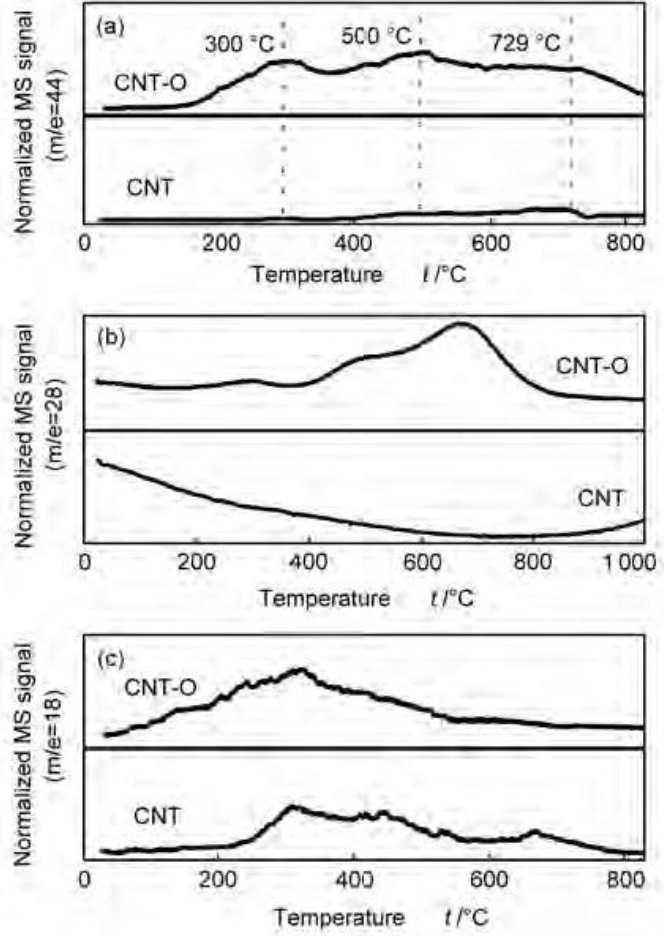

Fig. 6: (a): $\mathrm{CO}_{2}$ TPD profile and (b, c): $\mathrm{CO}$ and $\mathrm{H}_{2} \mathrm{O}$ TPD profiles of CNT and CNT-O

The powder X-ray diffraction (XRD) analysis was performed on a STOE STADI-P transmission diffractometer equipped with a focusing primary Ge (111) monochromator and a position sensitive detector, using $\mathrm{Cu}-$ $\mathrm{K} \alpha 1$ radiation. Specific surface areas were measured by nitrogen adsorption at $77 \mathrm{~K}$ using an AUTOSORB-1-C physisorption/ chemisorption analyzer (Quantchrome). Xray photoelectron spectroscopy (XPS) was measured at beam line U49/2-PGM1 at BESSY in Berlin. Scanning electron microscopy (SEM) analysis was performed on a Hitachi S-4800 at an acceleration electron voltage of 15 $\mathrm{kV}$. Micrographs from transmission electron microscope (TEM) were taken on a Philips CM $200 \mathrm{LaB} 6$ at an acceleration voltage of $200 \mathrm{kV}$. Zeta-potential measurement was performed in a Malvern zetasizer. Approximately $10 \mathrm{mg}$ of CNTs was dispersed in $10 \mathrm{~mL}$ water and ultrasonicated for $10 \mathrm{~min}$. Then, zeta potential was measured at $25^{\circ} \mathrm{C}$ from $\mathrm{pH} 1.5$ to 12 , which was adjusted by using $0.25 \mathrm{~mol} / \mathrm{L} \mathrm{HCl}$ or $\mathrm{NaOH}$.

Adsorption isotherms of heavy metal ions at room temperature were obtained by adding $10 \mathrm{mg}$ CNT or CNT$\mathrm{O}$ to a $2 \mathrm{~mL}$ Eppendorf tube containing $1.5 \mathrm{~mL}$ of the appropriate adsorbate solution with different concentrations. The $\mathrm{pH}$ calculated for $\mathrm{CrO}_{4}{ }^{2-}$ (not adjusted with additional buffer) is around 7.8, which ensures that the sole species adsorbed was bianionic $\mathrm{CrO}_{4}{ }^{2-}$ during the adsorption experiments. The suspensions were kept for 5 days to ensure an equilibrium adsorption of heavy metal ions on the carbon. The $\mathrm{pH}$ at the adsorption equilibrium is about 5.9. The 

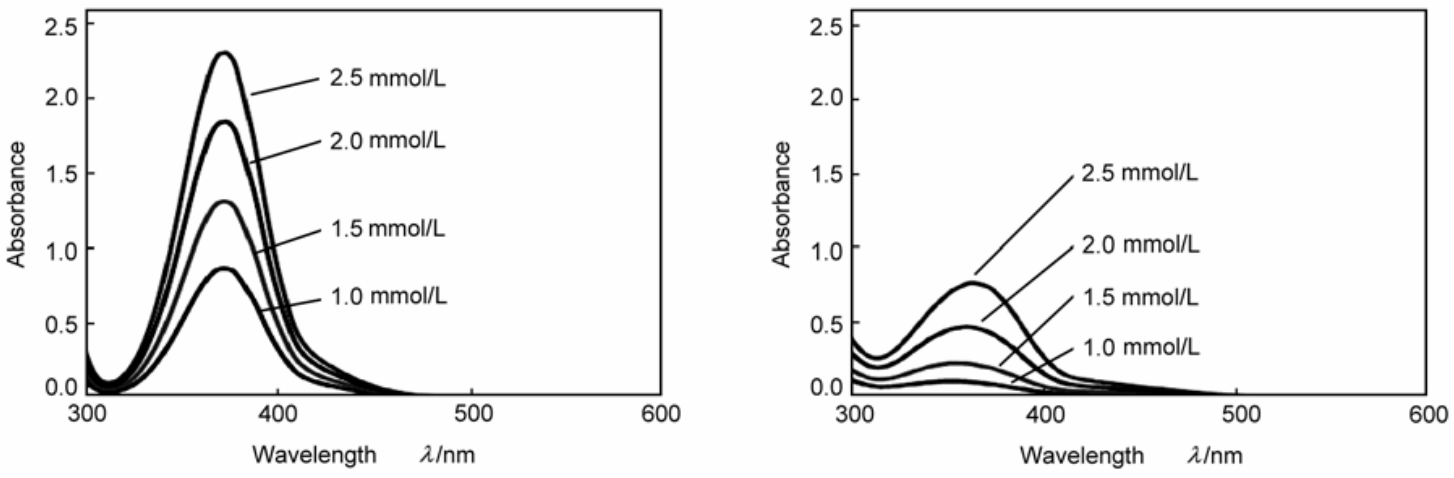

Fig.7: UV-Vis adsorption spectra of the chromate solution after adsorption by the samples of CNT (left) and CNT-O (right)
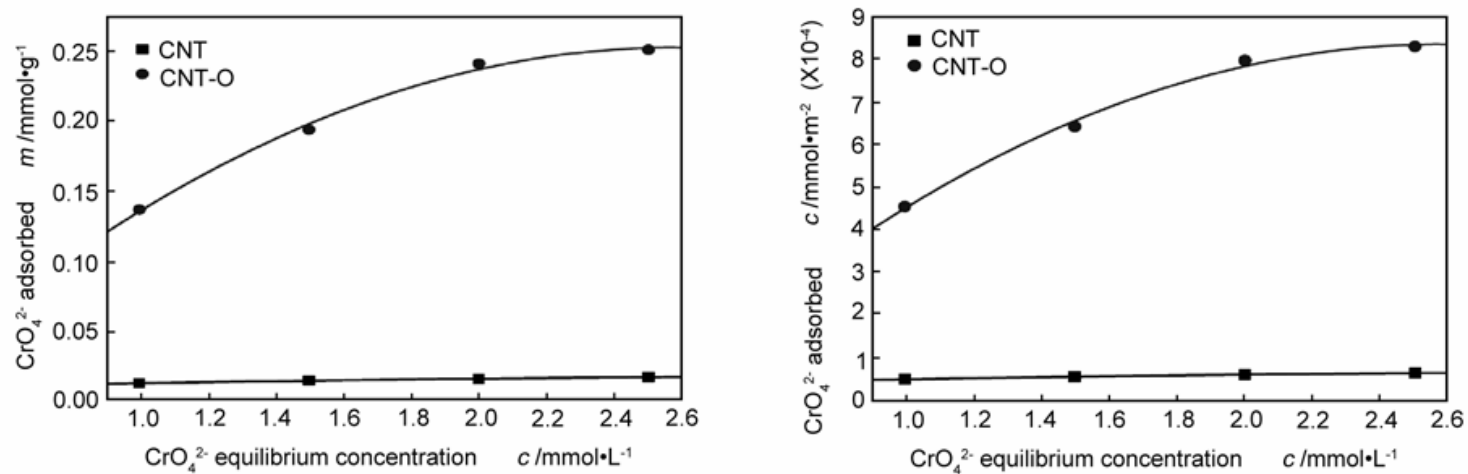

Fig.8: Adsorption isotherms of $\mathrm{CrO}_{4}{ }^{2-}$ per unit mass (top) and per unit surface area (bottom) in aqueous solution on the samples of CNT and CNT-O

concentration of $\mathrm{CrO}_{4}{ }^{2-}$ after adsorption was measured by Perkin-Elmer Lambda 650 UV/Vis spectrometer.

\section{Results and discussion}

Fig.1 shows the SEM images of the as-received CNTs. It is found that CNTs are evenly and well distributed, and no amorphous carbon is detected. Details of the microstructure of the wall and surface structure of CNTs are revealed by TEM and high-resolution TEM images, as shown in Fig.2. Clearly, the walls of these CNTs exhibit well-graphitized structure, and no amorphous carbon is present. The distribution of outer diameters is shown in Fig.2, illustrating that the average diameter of the CNTs is around $5 \mathrm{~nm}$.

Fig. 3 shows the nitrogen adsorption-desorption isotherms and pore size distribution of the original CNTs and the functionalized CNT-O. The specific Brunauer-EmmettTeller(BET) surface area and micropore volume of CNTs are $293 \mathrm{~m}^{2} \cdot \mathrm{g}^{-1}$ and $0.12 \mathrm{~cm}^{3} \cdot \mathrm{g}^{-1}$, respectively. After oxidation treatment, the specific BET surface area of CNT-O is increased to $301 \mathrm{~m}^{2} \mathrm{~g}^{-1}$ and the micropore volume is 0.13 $\mathrm{cm}^{3} \cdot \mathrm{g}^{-1}$. XRD patterns shown in Fig.4 indicate no significant difference observed between CNTs and CNT-O.
The remarkably increased amount of oxygencontaining functional groups on the CNT-O as compared with the unmodified CNTs has been illustrated by XPS analysis. Based on the areas of the $\mathrm{O} 1 \mathrm{~s}$ and $\mathrm{C} 1 \mathrm{~s}$ peaks in the spectra, the surface composition of the original CNTs and the as-functionalized CNT-O can be quantified. Results showing the difference in surface functional groups of the CNTs and the CNT-O are shown in Fig.5, which clearly suggests that the CNT-O be loaded with oxygen-containing surface functional groups. The surface oxygen content on the CNT-O is calculated to be $22 \%$, whereas the original CNTs has a surface oxygen content of only ca. 3\%. Further deconvolution of the O1s peaks in the spectra is depicted in Fig.5. The O1s spectra of the CNT-O can be deconvoluted into four peaks [16-18]. The peak at around $531.2 \mathrm{eV}$ corresponds to carbonyl $/ \mathrm{C}=\mathrm{O}$ species and the peaks at $532.1 \mathrm{eV}$ and $533.4 \mathrm{eV}$ to the $\mathrm{C}-\mathrm{O}$ and hydroxyl/ $\mathrm{C}-\mathrm{OH}$ moiety. The small peak at $535.8 \mathrm{eV}$ is assigned to adsorbed water.

The feature of the more abundant oxygen-containing functional groups on the CNT-O than that on CNTs has been also corroborated qualitatively by the TPD profile obtained under helium atmosphere. It can be seen from Fig.6 that the intensity of $\mathrm{CO}_{2}, \mathrm{CO}$, and $\mathrm{H}_{2} \mathrm{O}$ in TPD profiles of CNT-O is much higher than that of CNTs. Further deconvolution of the $\mathrm{CO}_{2}$ in TPD profile gives three main 
peaks located around $300^{\circ} \mathrm{C}, 500{ }^{\circ} \mathrm{C}$, and $700{ }^{\circ} \mathrm{C}$, which can be attributed to anhydride, carboxylic, carbonyl, and lactone groups [19]. Clearly, all of these types of acidic functional groups have been significantly increased after the functionalization by oxidation, thereby making CNTs more active for capturing heavy metal ions from aqueous solution. Adsorption of heavy metal ions on CNTs or activated carbon is generally related to the surface functional groups [9, 20-22].

The functionalized CNT-O and original CNTs have been used for testing their capability for adsorption of anionic chromate $\left(\mathrm{CrO}_{4}{ }^{2-}\right)$, a typical heavy metal ion in waste water. Figs.7 and 8 show the UV-Vis spectra of solution after the adsorption equilibrium is reached and the corresponding $\mathrm{CrO}_{4}{ }^{2-}$ adsorption isotherms on CNTs and CNT-O in aqueous solution. Obviously, the sample CNT-O with the abundant oxygen-containing surface functional groups, particularly the $\mathrm{OH}$ groups, has the excellent $\mathrm{CrO}_{4}{ }^{2-}$ adsorption capacity because the adsorption of $\mathrm{CrO}_{4}{ }^{2-}$ occurs mainly via ion exchange with acidic surface $\mathrm{OH}$ groups [23-25].

In addition, the adsorption isotherm of $\mathrm{CrO}_{4}{ }^{2-}$ on the CNT-O fits well with Langmuir model, from which a maximum adsorption capacity of $249 \mu \mathrm{mol} / \mathrm{g}$ can be extracted for CNT-O. In contrast, the original CNTs exhibit a poor maximum adsorption capacity of $16 \mu \mathrm{mol} / \mathrm{g}$, which can be accounted for by the very low oxygen-containing surface functional groups in the original CNTs. In other words, the adsorption capacity of $\mathrm{CrO}_{4}{ }^{2-}$ from aqueous solution on the CNT-O is 15 times as large as that on the CNTs. Similar results are obtained if the adsorption capacity is based on surface area. The estimated maximum adsorption capacity per unit surface area on the CNT-O is $0.83 \mu \mathrm{mol} / \mathrm{m}^{2}$, which is pretty higher than $0.06 \mu \mathrm{mol} / \mathrm{m}^{2}$ on the CNTs. Therefore, based on both the adsorption capacity per unit mass and per unit surface area, the CNT-O exhibits the superior performance for capturing $\mathrm{CrO}_{4}^{2-}$ from aqueous solution. Zetapotential analysis demonstrates that the CNT-O is negative-

\section{References}

[1] Gogotsi Y. Carbon Nanomaterials[M].Boca Raton: CRC, 2006.

[2] Benedek G, Milani P, Ralchenko V G. Nanostructured Carbon for Advanced Applications[M].Dordrecht: Kluwer, 2000.

[3] Jiang Q, Chen Z P. Thermodynamic phase stabilities of nanocarbon[J]. Carbon, 2006, 44: 79-83.

[4] Goettmann F, Fischer A, Antonietti M, et al. Chemical synthesis of mesoporous carbon nitrides using hard templates and their use as a metal-free catalyst for friedel-crafts reaction of benzene[J]. Angew Chem Int Ed, 2006, 45: $4467-$ 4471.

[5] Guldi D M, Rahman G M A, Zerbetto F, et al. Carbon nanotubes in electron donor-acceptor nanocomposites[J] Acc Chem Res, 2005, 38: 871-878.

[6] Terrones M. Science and technology of the twenty-first century: synthesis, properties and applications of carbon nanotubes[J]. Annu Rev Mater Res, 2003, 33: 419-501. ly charged on the surface in the range of $\mathrm{pH}>3.5$, and bianionic $\mathrm{CrO}_{4}{ }^{2-}$ is the predominant species in this $\mathrm{pH}$ range [25]. Hence, these exclude the electrostatic effect as the main contribution to the adsorption of $\mathrm{CrO}_{4}{ }^{2-}$ from aqueous solution using the functionalized CNT-O as adsorbent. However, the contribution of BET surface area and micropore volume to the difference in adsorption capability of $\mathrm{CrO}_{4}{ }^{2-}$ for the original CNTs and functionalized CNT-O can also be excluded because of negligible change of their BET surface area and micropore volume as mentioned above. Thus, the superior adsorption capability of chromate on the CNT-O as compared with the CNTs can be ascribed to the interaction of chromate with the abundant surface oxygen-containing functional groups on the CNT-O.

\section{Conclusion}

We have investigated the adsorption of anionic chromate, a typical heavy metal ion in waste water, using functionalized CNTs as adsorbent. The features of abundant oxygen- containing surface functional groups on the functionalized CNT were characterized by the XPS and TPD analyses, which are ascribed to the excellent adsorption capacity of chromate as compared with the unmodified CNTs. The results herein have demonstrated that functionalized CNTs with abundant oxygen-containing surface functional groups have the significant potential as a viable adsorbent for the removal of chromate from aqueous solution.

\section{Acknowledgement}

The financial support from EnerChem project of the Max Planck Society, Germany, is gratefully acknowledged.

[7] Ajayan P M. Nanotubes from carbon[J]. Chem Rev, 1999, 99: $1787-1800$.

[8] Tasis D, Tagmatarchis N, Bianco A, et al. Chemistry of carbon nanotubes[J]. Chem Rev, 2005, 106: 1105-1136.

[9] Rao G P, Lu C, Su F. Sorption of divalent metal ions from aqueous solution by carbon nanotubes: A review[J]. Sep Purif Technol, 2007, 58: 224-231.

[10] Brown P A, Gill S A, Allen S. Metal removal from wastewater using peat[J]. Water Res, 2000, 34: 3907-3916.

[11] Alloway B J, Ayres A K. Chemical Principles of Environmental Pollution (2nd Ed.)[M]. Blackie Academic and Professional, 1997.

[12] Deng S, Bai, R. Removal of trivalent and hexavalent chromium with aminated polyacrylonitrile fibers: performance and mechanisms[ J]. Water Res, 2004, 38: 2424-2432.

[13] Kowalski Z. Treatment of chromic tannery wastes[J]. J Hazard Mater, 1994, 37: 137-141 
[14] Goswami S, Ghosh U C. Studies on adsorption behaviour of Cr (VI) onto synthetic hydrous stannic oxide[J]. Water SA, 2005, 31: 597-602.

[15] Vix-Guterl C, Couzi M, Dentzer J, et al. Surface characterizations of carbon multiwall nanotubes: comparison between surface active sites and raman spectroscopy[J]. J Phys Chem B, 2004, 108: 19361-19367.

[16] Liu X, Su D S, Schlögl R. Oxidative dehydrogenation of 1butene to butadiene over carbon nanotube catalysts[J]. Carbon, 2008, 46: 547-549.

[17] Arrigo R, Hävecker M, Schlögl R . Dynamic surface rearrangement and thermal stability of nitrogen functional groups on carbon nanotubes[J]. Chem Commun, 2008: 4891-4893.

[18] Arrigo R, Hävecker M, Wrabetz S, et. al., Tuning the Acid/Base Properties of Nanocarbons by Functionalization via Amination[J]. J Am Chem Soc, 2010, 132(28): 9616-9630.

[19] Zhou J, Sui Z, Zhu J, et al. Characterization of surface oxygen complexes on carbon nanofibers by TPD, XPS and FTIR[J]. Carbon, 2007, 45: 785-796.

[20] García-Martín J, López-Garzón R, Luz Godino-Salido M, et. al., Ligand adsorption on an activated carbon for the removal of chromate ions from aqueous solutions[J]. Langmuir, 2005, 21: 6908-6914.
[21] Carrott P J M, Carrott M M L, Nabais J M V, et al. Influence of surface ionization on the adsorption of aqueous zinc species by activated carbons[J]. Carbon, 1997, 35: 403-410.

[22] Vinke P, van der Eijk M, Verbree M, et. al., Modification of the surfaces of a gas-activated carbon and a chemically activated carbon with nitric acid, hypochlorite, and ammonia[J]. Carbon, 1994, 32: 675-686.

[23] Xu Y J, Weinberg G, Liu X, et. al., Nanoarchitecturing of activated carbon: facile strategy for chemical functionalization of the surface of activated carbon[J]. Adv Funct Mater, 2008, 18: 3613-3619.

[24] Su D S, Chen X, Weinberg G, et. al., Hierarchically structured carbon: synthesis of carbon nanofibers nested inside or immobi lized onto modified activated carbon[J]. Angew Chem Int Ed, 2005, 44: 5488-5492.

[25] Arup K S, Dennis C. Important process variables in chromate ion exchange[J]. Environ Sci Technol., 1986, 20: 149-155. 